\title{
Novos Materiais
}

\section{PLÁSTICOS}

A indústria dos plásticos tem sofrido nos últimos anos um desenvolvimento espectacular e a prová-lo parece estar a apresentação pública de novos materiais por diversas empresas de renome.

No passado mês de Novembro, por exemplo, a Bayer AG participou em Dusseldorf na Feira dos Plásticos (K' 89 ) onde introduziu uma série de novos produtos e aplicações para os seus polímeros técnicos em seis áreas distintas:

\section{- novos plásticos:}

(i) ${ }^{\mathrm{R}}$ Apec - material da família dos policarbonatos com resistência dimensional ao calor até $238^{\circ} \mathrm{C}$;

(ii) ${ }^{\mathrm{R}}$ Tedur - termoplástico de alto rendimento à base de PPS, para as indústrias automobilísticas e electrónica;

(iii) ${ }^{\mathrm{R}}$ Polystal - produto semi-acabado de alto rendimento com ligante termoplástico;

(iv) ${ }^{\mathrm{R}}$ Makrolon - produto para fibras ópticas.

\section{- aplicaçōes dos poliuretanos:}

(i) ${ }^{\text {R} B a y t e c ~-~ e l a s t o ́ m e r o ~ d e ~ p o l i u r e t a n o ~ u s a d o ~ p a r a ~ r e v e s t i r ~}$ rolos e cilindros que sejam sujeitos a cargas máximas;

(ii) ${ }^{\mathrm{R}}$ Bayflex 150 - poliureia, que por oferecer vantagens de transformação em relação aos poliuretanos RIM tradicionais e ser mais resistente à temperatura e mais rígido, tem como principal campo de aplicação a indústria automóvel;

$\mathrm{Na}$ perspectiva dos produtos compatíveis com o meio ambiente foram ainda apresentadas novas dispersões de poliuretano para a fabricação de adesivos (produto que será conhecido comercialmente como ${ }^{\mathrm{R}}$ Dispercoll U), com excelente aderência aos mais diversos substratos, nomeadamente ao PVC com elevada percentagem de plastificante e a couros. As colagens têm também boa resistência ao calor e graças a estas propriedades são já empregues no sector automóvel para o fabrico de forros, prevendo-se no futuro aplicações na indústria de móveis para o tratamento da superfície de placas prensadas, na indústria de curtumes para a laminação de couros divididos com PVC e na indústria do calçado para a colagem de solas.

\section{- borrachas:}

(i) ${ }^{\mathrm{R}}$ Terban - elastómero nitrílico hidrogenado muito resistente à abrasão e de alto rendimento, capaz de suportar grandes cargas dinâmicas e mecânicas e que, além disso, apresenta uma margem de aplicação entre $-40 \mathrm{oC}$ e mais +150 oC e não intumesce em contacto com os mais variados fluídos operacionais;

(ii) polibutadieno de neodímio - elastómero a utilizar na indústria de pneus;

(iii) ${ }^{\mathbf{R}}$ Desmopan - elastómero de poliuretano, reticulável por radiação;

(iv) KA 9124 e KA 9131 - aceleradores isentos de nitrosaminas, usados para a vulcanização da borracha. A importância destes aceleradores reside no facto das nitrosaminas se terem revelado cancerígenas em ensaios com animais e os aceleradores de vulcanização libertarem aminas secundárias susceptíveis de formar compostos nitrosos estáveis que à semelhança de outros produtos amínicos podem dar origem àquelas substâncias indesejáveis. Muito embora não tenham sido ainda encontrados produtos de substituição para todos os casos, existem já soluções adequadas para os aceleradores de sulfenamidas - frequentemente utilizados na indústria de pneus - através do uso do produto ${ }^{\mathrm{R}}$ Vulkacit AMZ que apresenta praticamente o mesmo comportamento na vulcanização que $\mathrm{o}^{\mathrm{R}}$ Vulkacit $\mathrm{MOZ}$, que é perigoso do ponto de vista toxicológico; e para os aceleradores de tiuramas - utilizados no fabrico de artigos técnicos de borracha de grande resistência ao calor como anéis de vedação, mangueiras e elementos de amortecimento - através do uso do produto KA 9131 que não forma nitrosaminas e satisfaz as exigências impostas para diversos polímeros como dador de enxofre.

\section{- produtos químicos inorgânicos:}

Nesta divisão foi demostrada a grande versatilidade do ${ }^{R}$ Silopren, borracha de silicone, e apresentados sistemas de borracha de silicone líquida para os quais se antevêem interessantes aplicações, como por exemplo, as borrachas autolubrificantes e resistentes às chamas.

\section{- pigmentos e cerâmicas:}

Foram apresentados pigmentos inorgânicos brancos e de cor para a coloração de plásticos e fibras de vidro para reforçar materiais termoestáveis e termoplásticos.

\section{- tintas e vernizes e campos especiais:}

O tema base desta área foi «novos sistemas para a construção civil» e a informação incidiu sobre apoios amortecedores de vibrações, revestimentos para a vedação de edifícios e fixação química de buchas, sendo os novos sistemas químicos para a construção civil todos eles isentos de solventes. 
Ainda no domínio dos novos materiais, a Bayer AG desenvolveu recentemente um novo aditivo à base de um composto de boro para incorporar em sistemas de aderência contendo compostos de cobalto, por exemplo, naftenato, estearato ou neodecanoato de cobalto, destinados ao fabrico de revestimentos de cabo de aço. Este novo aditivo proporciona uma maior aderência e graus mais elevados de cobertura dos cabos de aço, em particular após sobrevulcanização e envelhecimento por vapor, o que o torna especialmente indicado dado que os revestimentos devem apresentar uma longa durabilidade e uma boa capacidade de recuperação.

Para complementar toda esta dinâmica de inovação e no seguimento do estabelecimento de um banco de dados sobre materiais, conhecido por Campus, a Bayer oferece agora aos seus clientes um novo sistema de informação em diskettes sobre plásticos, que contém dados de materiais, instruções técnicas e programas de cálculo para o desenvolvimento e desenho de peças de plástico e que se chamará Baydisk. Tal como no caso de Campus, também os programas Baydisk são lidos por computadores pessoais IBM ou compatíveis e estão disponíveis em quatro versões:

- RALPH - programa destinado a determinar os limites de carga dos termoplásticos da Bayer sob esforços mecânicos, tendo em conta o tipo de carga (estática de curta duração, estática de longa duração, dinâmica ou de impacto), as condições exteriores (temperatura, humidade, agentes agressivos) e as características estruturais internas ou externas (costuras, entalhes, orientação das fibras de vidro, etc);

- FLAEMO - programa orientado para a determinação de momentos de inércia superficiais, pontos de gravidade, distâncias das fibras periféricas e áreas correspondentes a quaisquer secções;
- FINEL - programa vocacionado para o cálculo de tensões, alongamentos e deformações de suportes de geometria, secção e condições marginais variáveis, podendo ter em conta relações não lineares no caso de grandes deformações;

- BAYMAT - programa que compreende dados térmicos e reológicos para o dimensionamento das peças de moldagem e dos moldes.

Por seu turno a EVC (European Vinyls Corporation), considerada o maior fabricante europeu de vinilos, entrou no negócio da reciclagem de plásticos juntamente com a PVC Reclamation Lda.. A operação de reciclagem compreende o tratamento dos desperdícios plásticos quer industriais quer pós-consumíveis.

A EVC estabeleceu também um acordo de cooperação com a firma japonesa Kaneka, produtora de materiais brutos de plásticos, no campo da engenharia de alta "performance» de produtos poliméricos, para ser usada no mercado europeu de equipamento automático para escritórios como fax, impressoras (incluindo as de raios laser), monitores, teclados, fotocopiadoras, máquinas de escrever e periféricos. A superioridade das ligas de PVC desenvolvidas relativamente aos compostos tradicionais e aos polímeros alternativos resulta da nova tecnologia que alia as forças inerentes à base do polímero com propriedades de fluxo melhoradas para facilitar a moldagem, e avanços significativos na estabilidade da luz UV, na força de impacto e no comportamento de amolecimento a altas temperaturas.

FILOMENA MARTINS

Departamento de Química Faculdade de Ciências de Lisbo:

\section{SPQ - QUOTAS}

Sócio Efectivo

$2000 \$ 00$

Estudante $650 \$ 00$

\section{BOLETIM}
Assinatura (4 números)
......................
Número avulso
$1500 \$ 00$ (no país)
US\$35 (no estrangeiro)
$330 \$ 00$
$(+150 \$ 00$ de porte de correio) 